\title{
BMJ
}

\section{Participation in life situations of 8-12 year old children with cerebral palsy: cross sectional European study}

Jérôme Fauconnier, specialist in public health, ${ }^{1}$ Heather 0 Dickinson, reader in epidemiology, ${ }^{2}$ Eva Beckung,
associate professor in physical therapy, ${ }^{3}$ Marco Marcelli, specialist in paediatric neuropsychiatry, ${ }^{4}$ Vicki
McManus, research coordinator, ${ }^{5}$ Susan I Michelsen, researcher in child health, ${ }^{6}$ Jackie Parkes, senior lecturer
in nursing, ${ }^{7}$ Kathryn N Parkinson, senior research associate, ${ }^{2}$ Ute Thyen, professor of paediatrics, ${ }^{8}$ Catherine
Arnaud, associate professor in public health, ${ }^{9}$ Allan Colver, Donald Court professor of community child health ${ }^{2}$

'Université Joseph Fournier, DIMPôle Santé Publique Equipe

ThEMAS, CHU de Grenoble BP 217, 38043 Grenoble Cedex 9, France

${ }^{2}$ Institute of Health and Society, Newcastle University, Newcastle upon Tyne NE1 7RU

${ }^{3}$ Göteborg University, Queen Silvia Children's Hospital, S-41685 Gothenburg, Sweden

${ }^{4}$ Azienda Sanitaria Locale Viterbo, Viale Trento 18 H, 01100 Viterbo, Italy

${ }^{5}$ Enable Ireland, Lavanagh Centre, Ballintemple, Cork, Republic of Ireland

${ }^{6}$ National Institute of Public Health, University of Southern Denmark, Oster Farimagsgade 5A, 1399 Copenhagen, Denmark

${ }^{7}$ School of Nursing and Midwifery, Queen's University Belfast, Belfast BT9 5BN

${ }^{8}$ Klinik für Kinder und Jugendmedizin,

Universitätsklinikum SchleswigHolstein, Ratzeburger Allee 160, 23538 Lübeck, Germany

${ }^{9}$ Institut National de la Santé et de la Recherche Médicale, Université Paul Sabatier, Faculté de Médecine, 37 allées J Guesde, 31073 Toulouse, France

Correspondence to: A Colver

allan.colver@ncl.ac.uk

Cite this as: BMJ 2009;338:b1458 doi:10.1136/bmj.b1458

\section{ABSTRACT}

Objectives To evaluate how involvement in life situations (participation) in children with cerebral palsy varies with type and severity of impairment and to investigate geographical variation in participation.

Design Cross sectional study. Trained interviewers visited parents of children with cerebral palsy; multilevel multivariable regression related participation to impairments, pain, and sociodemographic characteristics.

Setting Eight European regions with population registers of children with cerebral palsy; one further region recruited children from multiple sources.

Participants 1174 children aged 8-12 with cerebral palsy randomly selected from the population registers, 743

(63\%) joined in the study; the further region recruited 75 children.

Main outcome measure Children's participation assessed by the Life-H questionnaire covering 10 main areas of daily life. Scoring ignored adaptations or assistance required for participation.

Results Children with pain and those with more severely impaired walking, fine motor skills, communication, and intellectual abilities had lower participation across most domains. Type of cerebral palsy and problems with feeding and vision were associated with lower participation for specific domains, but the sociodemographic factors examined were not. Impairment and pain accounted for up to a sixth of the variation in participation. Participation on all domains varied substantially between regions: children in east Denmark had consistently higher participation than children in other regions. For most participation domains, about a third of the unexplained variation could be ascribed to variation between regions and about two thirds to variation between individuals.

Conclusions Participation in children with cerebral palsy should be assessed in clinical practice to guide intervention and assess its effect. Pain should be carefully assessed. Some European countries facilitate participation better than others, implying some countries could make better provision. Legislation and regulation should be directed to ensuring this happens.

\section{INTRODUCTION}

Article 23 of the UN Convention on the Rights of the Child, ratified by 192 nations, states that a mentally or physically disabled child should have the opportunity to participate and to have access to services to promote participation. ${ }^{1}$ Articles 23-30 of the 2006 UN Convention on the Rights of Persons with Disabilities, so far ratified by 34 nations, state that children with disabilities should be able to participate on an equal basis with others in family life, health maintenance, education, public life, and recreational, leisure, and sporting activities. $^{2}$

In the past decade, concepts of disability and disadvantage for children with impairments have become clearer, largely due to the World Health Organization's International Classification of Functioning, Disability and Health $(\mathrm{ICF})^{3}$ and its version for children and young people. ${ }^{4}$ Since their publication, interest has focused less on actual impairments and more on the impact of the impairments on the personal and social life of the individual. The classification defines "participation" as involvement in life situations; it is understood to be a consequence of a dynamic interaction between a person and environmental factors rather than a direct consequence of illness. Disabled children experience difficulty in participating across a wide range of domains. ${ }^{56}$ These include non-discretionary aspects of participation that are essential to daily life, such as eating, sleeping, and toileting.

The classification is consistent with the social model of disability, ${ }^{7}$ which regards disability as a consequence of the failure of the environment to be adjusted sufficiently to meet the needs of the individual. ${ }^{89}$ The social model predicts that participation will vary between countries.

Cerebral palsy is the commonest cause of severe motor impairment in childhood, with a rate of about 2.5 per 1000 live births. ${ }^{10}$ Affected children have various types and severities of impairments ${ }^{1112}$ and so 
might be regarded as typical of a wide range of disabled children.

Many studies of participation in affected children are unsatisfactory because of inadequate sample size, ${ }^{13}$ non-representative convenience samples, ${ }^{1415}$ use of instruments that do not capture the modern concept of participation, ${ }^{16-18}$ or neglect of social dimensions of participation. ${ }^{19-21}$

In a large representative sample of children with cerebral palsy we evaluated how participation varied with type and level of impairment and with pain and assessed the geographical variation predicted by the social model of disability.

\section{METHODS}

The study is part of a wider project, SPARCLE (www. ncl.ac.uk/sparcle), ${ }^{22}$ which examines the relation of the quality of life and participation of children with cerebral palsy to their environment within the conceptual framework of the social model of disability. ${ }^{7}$ The SPARCLE protocol, sampling strategy, recruitment rates, and potential for bias have been reported in detail elsewhere. ${ }^{223}$

Eligible children were those born from 31 July 1991 to 1 April 1997 and on population registers of children with cerebral palsy in eight regions of six European countries that share a standardised definition and classification of cerebral palsy ${ }^{10}$ : south east France, south west France, south west Ireland, west Sweden, north England, Northern Ireland, east Denmark, and central Italy. There were 1884 such children. In regions with more than 200 registered children (west Sweden, north of England, Northern Ireland, east Denmark), we sampled so that the number agreeing to participate would be between 100 and 120 with similar numbers of children at each level of severity; we did this by grouping children by walking ability and selecting random samples within strata in each region. ${ }^{23}$ In other regions we approached all eligible children. We sampled 1174 eligible families, of whom $743(63 \%)$ took part. We were unable to trace $12 \%$ of families sampled; of those traced, $73 \%$ agreed to take part, $3 \%$ were not approached, and $24 \%$ declined to take part. ${ }^{23}$ A further region in north west Germany recruited 75 children from multiple sources and used the same classification of cerebral palsy ${ }^{10}$; the age, sex, and levels of impairment of these children were similar to those of eligible children recorded on the population based registers. ${ }^{23}$ Thus the sample comprised 818 children. Table 1 shows the numbers in each region.

Research associates visited children at home in 2004-5 to administer questionnaires to parents and children, if possible when the children were aged 8 12. To suit family circumstances, they interviewed 20 children just outside this age range.

Participation was assessed with the Life-H questionnaire. ${ }^{13}$ This instrument was developed from a strong theoretical framework aligned with WHO's international classification, ${ }^{3}$ is validated in disabled children, ${ }^{13}$ and has been used with children with cerebral palsy. ${ }^{24}$ It comprises 62 items grouped into 11 domains covering both daily activities and social roles. We omitted one question about sexual relations as it was not appropriate to this age group. Fifteen of the items concern non-discretionary participation regarded as essential to a child's daily life and for these the parent is asked if the child achieves it with or without difficulty. For the 47 other items the parent is asked if the child achieves it and, if so, whether with or without difficulty.

All items also ask whether the child needs help or the use of aids and adaptations to participate and, if so, what type of help. The scoring system scores participation as lower not only if the child has greater difficulty in participation but also if more assistance is needed. As we wanted to assess difficulty in participation without making assumptions about how it was influenced by environmental factors, our main analysis ignored the questions about assistance.

We assessed frequency and severity of pain in the previous week using the two questions about pain from the child health questionnaire. ${ }^{25}$ We used parents' reports of their child's pain because we were examining participation for children of all cognitive abilities and we considered it more valid to report pain in a similar way across all the children (that is, those who could and could not self report).

Parents provided information about their employment and level of educational qualifications, whether they lived in an urban or rural area, their child's age, sex, impairments (gross motor function, ${ }^{26}$ fine motor skills, ${ }^{18}$ intellectual ability, vision, hearing, seizures, feeding, communication), and school type, and number and disability of any siblings. Data on type of cerebral palsy were available from the registers.

\section{Statistical methods}

The statistical methods are described in detail in appendix 1 on bmj.com and summarised here. We coded responses to non-discretionary items as binary variables (with or without difficulty) and responses to discretionary items as ordinal variables (performed without difficulty, performed with difficulty, not performed because too difficult, missing if not performed for other reasons).

We analysed each domain separately. We also analysed all non-discretionary items grouped together as

Table 1| Number and percentage of children with cerebral palsy by region

\begin{tabular}{lc} 
Region & No (\%) \\
South east France & $67(8)$ \\
\hline South west France & $77(9)$ \\
\hline North west Germany & $75(9)$ \\
\hline South west Ireland & $98(12)$ \\
\hline West Sweden & $83(10)$ \\
\hline North England & $116(14)$ \\
\hline Northern Ireland & $102(12)$ \\
\hline East Denmark & $115(14)$ \\
\hline Central Italy & $85(10)$ \\
\hline
\end{tabular}


non-discretionary participation might be less subject to cultural influences than discretionary participation and so might be a better indicator of how well a region facilitates participation of disabled children.

We assumed that children's participation within each domain could be summarised by a single variable and that, although this variable could not be observed or measured directly, it determined the parents' responses to the items. We refer to these unobserved variables as "factors" but they are sometimes referred to as latent variables or latent traits. ${ }^{27}$ In the same way, we assumed that non-discretionary participation could be summarised by a single factor that determined parents' responses to all non-discretionary items. We estimated each factor (that is, the child's level of participation on each domain) and related it to covariates-sociodemographic characteristics, impairment, and pain - in a single, unified, multilevel model that allowed for clustering of children within regions. The mean child participation, after adjustment for significant covariates, was assumed to be zero.

Frequency and severity of pain were highly correlated (Spearman's rank correlation coefficient $=0.83$ ) so we arbitrarily included its frequency rather than its severity in the model. We used forwards stepwise regression followed by backwards steps to select covariates to enter into the model. To lessen the probability of chance findings caused by multiple hypothesis testing, we set the $\mathrm{P}$ value for entry and removal of covariates at 0.01 . The final models exclude the 19 children with missing data on impairment and pain and, additionally, any children with missing data on participation. As an indicator of the variation in participation explained by the covariates, we noted the percentage reduction in the log likelihood relative to a multilevel model with no covariates. We present results as odds ratios with $95 \%$ confidence intervals. For each type of impairment, these odds ratios compare the participation of children with a specific severity of impairment with the participation of the least impaired children. We estimated the significance of heterogeneity between regions by comparing the final multilevel, multivariate model with a similar model that did not allow for clustering within regions. We report the proportion of the total residual variance that is between regions. To assess goodness of fit we examined the distribution of residuals for each item. For comparison purposes, we also performed multivariable, multilevel logistic regression analysis using the conventional scoring of Life-H, dividing children into those with participation above and below the median on each domain.

Statistical analysis was performed with the GLAMM suite of programs ${ }^{28}$ in Stata 9.

\section{RESULTS}

The parents of 818 children were interviewed. Table 2 summarises the type and severity of the children's impairments and parental reports of their child's pain. Sociodemographic characteristics have been reported previously. ${ }^{29}$
Table $2 \mid$ Number and percentage of 818 children with cerebral palsy by impairment and level of pain

No (\%)

Gross motor function:

\begin{tabular}{ll}
\hline I Walks and climbs stairs, without limitation & $257(31)$ \\
\hline II Walks with limitations & $164(20)$ \\
\hline III Walks with assistive devices & $139(17)$ \\
\hline IV Unable to walk, limited self mobility & $113(14)$ \\
\hline V Unable to walk, severely limited self mobility & $145(18)$
\end{tabular}

Fine motor skills

I Without limitation 281 (34)

II Both hands limited in fine skills 205 (25)

III Needs help with tasks 131 (16)

IV Needs help and adapted equipment 91 (11)

$\checkmark$ Needs total human assistance 110 (13)

Intellectual impairment:

None or mild (IQ〉70) 385 (47)

Moderate (IQ 50-70) $186(23)$

Severe $(\mathrm{IQ}<50) \quad 242(30)$

Information not available 5 (1)

Vision:

Has useful vision 759 (93)

Blind or no useful vision 59 (7)

Hearing:

Does not need hearing aids 799 (98)

Needs hearing aids (>70 decibel loss) 18 (2)

Information not available $1(0)$

Seizures:

No seizures in previous year $650(79)$

Seizures in previous year $167(20)$

Information not available $1(0)$

Feeding:

No problems 583 (71)

Feeds orally with difficulty $176(22)$

Partial or complete feeding by tube 58 (7)

Information not available $1(0)$

Communication:

Normal speech $463(57)$

Difficulty but uses speech 133 (16)

Uses non-speech for formal communication 98 (12)

No formal communication 123 (15)

Information not available $1(0)$

Cerebral palsy subtype:

Unilateral spastic 279 (34)

Bilateral spastic $423(52)$

Dyskinetic 86 (11)

Ataxic 29 (4)

Information not available $1(0)$

Parental report of child pain in previous four weeks:

Amount of pain:

\begin{tabular}{|lc|}
\hline None & $240(29)$ \\
\hline Very mild or mild & $353(43)$ \\
\hline Moderate, severe, or very severe & $213(26)$ \\
\hline Information not available & $12(1)$ \\
\hline Frequency of pain: & $237(29)$ \\
\hline None of the time & $414(51)$ \\
\hline Once or twice or a few times & $155(19)$ \\
\hline More often & $12(1)$ \\
\hline Information not available
\end{tabular}


Tables 3 and 4 show the distribution of responses for each item of Life-H. All items, except one about school participation, had response rates of over $97 \%$. For 16 of the 47 discretionaryitems, however, over $10 \%$ of parents reported that their child did not participate for reasons other than difficulty-for example, the child was not interested or the activity was notavailable or not suitable for the child's age. We omitted community life from analysis because this domain was based on only two items (community groups and religious activities) and $18 \%$ of parents reported both items as irrelevant to their children; this problem was also encountered by the instrument's developers. ${ }^{13}$

In univariate analyses, all impairments except hearing and type of cerebral palsy were significantly associated with lower participation on all domains $(\mathrm{P}<0.01)$

Table 3 | Summary of responses to Life-H questions on daily activities in 818 children with cerebral palsy. Figures are numbers (percentages) of children

\begin{tabular}{|c|c|c|c|c|c|}
\hline & \multicolumn{2}{|c|}{ Achieved } & \multicolumn{2}{|c|}{ Not achieved } & \multirow[b]{2}{*}{$\begin{array}{l}\text { Response } \\
\text { missing }\end{array}$} \\
\hline & $\begin{array}{l}\text { Without } \\
\text { difficulty }\end{array}$ & $\begin{array}{c}\text { With } \\
\text { difficulty }\end{array}$ & $\begin{array}{c}\text { Too } \\
\text { difficult }\end{array}$ & $\begin{array}{l}\text { Other } \\
\text { reasons }\end{array}$ & \\
\hline \multicolumn{6}{|l|}{ Mealtimes } \\
\hline Eating meals* & $518(63)$ & $297(36)$ & NA & NA & $3(0)$ \\
\hline Selecting type and amount of food desired & $548(67)$ & $94(11)$ & $94(11)$ & $66(8)$ & $16(2)$ \\
\hline Taking part in preparing meals & $267(33)$ & $148(18)$ & $230(28)$ & $165(20)$ & $8(1)$ \\
\hline Eating out at restaurants, cafes, or fast food outlets & $508(62)$ & $208(25)$ & $70(9)$ & $24(3)$ & $8(1)$ \\
\hline \multicolumn{6}{|l|}{ Health hygiene } \\
\hline Getting in and out of bed* & $563(69)$ & $255(31)$ & NA & NA & $0(0)$ \\
\hline Getting a good sleep & 567 (69) & $107(13)$ & $111(14)$ & $16(2)$ & $17(2)$ \\
\hline Doing physical exercise for health & $366(45)$ & $310(38)$ & $90(11)$ & $44(5)$ & $8(1)$ \\
\hline Doing leisure pursuits for relaxation & $690(84)$ & $82(10)$ & $12(1)$ & $27(3)$ & $7(1)$ \\
\hline \multicolumn{6}{|l|}{ Personal care } \\
\hline Attending to personal hygiene ${ }^{\star}$ & $391(48)$ & $424(52)$ & NA & NA & $3(0)$ \\
\hline Toileting at home* & $495(61)$ & $317(39)$ & NA & NA & $6(1)$ \\
\hline Toileting away from home* & $430(53)$ & $375(46)$ & NA & NA & $13(2)$ \\
\hline Dressing and undressing upper half of body* & $358(44)$ & $457(56)$ & NA & NA & $3(0)$ \\
\hline Dressing and undressing lower half of body* & $338(41)$ & $475(58)$ & NA & NA & $5(1)$ \\
\hline Taking part in their own health care* & $476(58)$ & $329(40)$ & NA & NA & $13(2)$ \\
\hline $\begin{array}{l}\text { Using services provided by local doctor, hospital, or rehabilitation } \\
\text { centre* }^{\star}\end{array}$ & $522(64)$ & $277(34)$ & NA & NA & $19(2)$ \\
\hline Putting on and taking off his/her own aids & $233(28)$ & $100(12)$ & $265(32)$ & $214(26)$ & $6(1)$ \\
\hline \multicolumn{6}{|l|}{ Communication } \\
\hline Managing one-to-one communication with adults & $512(63)$ & $192(23)$ & $105(13)$ & $2(0)$ & $7(1)$ \\
\hline Managing one-to-one communication with young people & $495(61)$ & $168(21)$ & $145(18)$ & $4(0)$ & $6(1)$ \\
\hline Managing communication in group of people & $448(55)$ & $177(22)$ & $182(22)$ & $6(1)$ & $5(1)$ \\
\hline Writing & $301(37)$ & $181(22)$ & $320(39)$ & $14(2)$ & $2(0)$ \\
\hline Reading and understanding words, books, instructions, signs, etc & $384(47)$ & $208(25)$ & $217(27)$ & $2(0)$ & $7(1)$ \\
\hline Using telephone & $444(54)$ & $134(16)$ & $199(24)$ & $36(4)$ & $5(1)$ \\
\hline Using computer & $479(59)$ & $207(25)$ & $94(11)$ & $33(4)$ & $5(1)$ \\
\hline Using audiovisual equipment & $615(75)$ & $146(18)$ & $43(5)$ & $11(1)$ & $3(0)$ \\
\hline \multicolumn{6}{|l|}{ Home life } \\
\hline Entering and leaving home* & $560(68)$ & $255(31)$ & NA & NA & $3(0)$ \\
\hline Moving around home* & $619(76)$ & $197(24)$ & NA & NA & $2(0)$ \\
\hline Helping with housework & $301(37)$ & $145(18)$ & $259(32)$ & $112(14)$ & $1(0)$ \\
\hline Helping in garden or backyard & $228(28)$ & $110(13)$ & $264(32)$ & $214(26)$ & $2(0)$ \\
\hline $\begin{array}{l}\text { Managing common household things such as tables, light switches, } \\
\text { cupboards, doors }\end{array}$ & $522(64)$ & $116(14)$ & $169(21)$ & $5(1)$ & $6(1)$ \\
\hline Moving about just outside home & $517(63)$ & $223(27)$ & $65(8)$ & $8(1)$ & $5(1)$ \\
\hline \multicolumn{6}{|l|}{ Getting about } \\
\hline Moving about on streets and pavements* & $410(50)$ & $401(49)$ & NA & NA & $7(1)$ \\
\hline Moving about on slippery or uneven surfaces & $261(32)$ & $355(43)$ & $193(24)$ & $4(0)$ & $5(1)$ \\
\hline $\begin{array}{l}\text { Riding a bicycle, tricycle, scooters, rollerblades, wheelchair for } \\
\text { pleasure, etc }\end{array}$ & $385(47)$ & $223(27)$ & $174(21)$ & $32(4)$ & $4(0)$ \\
\hline Travelling as passenger in vehicles & $615(75)$ & $183(22)$ & $8(1)$ & $8(1)$ & $4(0)$ \\
\hline
\end{tabular}


Table 4 |Summary of responses to Life-H questions on social roles in 818 children with cerebral palsy. Figures are numbers (percentages) of children

\begin{tabular}{|c|c|c|c|c|c|}
\hline & \multicolumn{2}{|c|}{ Achieved } & \multicolumn{2}{|c|}{ Not achieved } & \multirow[b]{2}{*}{$\begin{array}{l}\text { Response } \\
\text { missing }\end{array}$} \\
\hline & $\begin{array}{l}\text { Without } \\
\text { difficulty }\end{array}$ & $\begin{array}{c}\text { With } \\
\text { difficulty }\end{array}$ & $\begin{array}{c}\text { Too } \\
\text { difficult }\end{array}$ & $\begin{array}{l}\text { Other } \\
\text { reasons }\end{array}$ & \\
\hline \multicolumn{6}{|l|}{ Responsibilities } \\
\hline Recognising money and using it correctly & $314(38)$ & $118(14)$ & $306(37)$ & $78(10)$ & $2(0)$ \\
\hline Managing pocket money & $291(36)$ & $74(9)$ & $302(37)$ & $151(18)$ & $0(0)$ \\
\hline Using bank or post office account & $101(12)$ & $25(3)$ & $278(34)$ & $411(50)$ & $3(0)$ \\
\hline Shopping or doing errands & $300(37)$ & $88(11)$ & $307(38)$ & $117(14)$ & $6(1)$ \\
\hline Respecting other people's property and rights & 547 (67) & 88 (11) & 159 (19) & $14(2)$ & $10(1)$ \\
\hline Taking responsibility for him/herself & $372(45)$ & $118(14)$ & $282(34)$ & $42(5)$ & $4(0)$ \\
\hline Supporting family members as needed & $513(63)$ & $87(11)$ & $177(22)$ & $38(5)$ & $3(0)$ \\
\hline \multicolumn{6}{|l|}{ Relationships } \\
\hline Maintaining loving relationship with parents & $760(93)$ & $45(6)$ & $8(1)$ & $1(0)$ & $4(0)$ \\
\hline $\begin{array}{l}\text { Maintaining loving relationship with other members } \\
\text { of family living at home }\end{array}$ & $635(78)$ & $57(7)$ & $7(1)$ & $116(14)$ & $3(0)$ \\
\hline Maintaining loving or social relationship with other relatives & $729(89)$ & $45(6)$ & $17(2)$ & $20(2)$ & $7(1)$ \\
\hline $\begin{array}{l}\text { Maintaining friendly links with other young people at school } \\
\text { or at leisure, etc }\end{array}$ & $626(77)$ & $127(16)$ & $43(5)$ & $14(2)$ & $8(1)$ \\
\hline Maintaining friendly links with other adults & $719(88)$ & $71(9)$ & $19(2)$ & $4(0)$ & $5(1)$ \\
\hline \multicolumn{6}{|l|}{ Community life } \\
\hline Taking part in activities of community groups & $277(34)$ & $90(11)$ & $193(24)$ & $256(31)$ & $2(0)$ \\
\hline Taking part in religious or spiritual activities & $210(26)$ & $70(9)$ & $117(14)$ & $406(50)$ & $15(2)$ \\
\hline \multicolumn{6}{|l|}{ School } \\
\hline Getting to school, entering and moving about within school and yard* & $539(66)$ & $265(32)$ & NA & NA & $14(2)$ \\
\hline Taking part in lessons, assignments, and assessments at school* & $434(53)$ & $367(45)$ & NA & NA & $17(2)$ \\
\hline Using school facilities* & $518(63)$ & $278(34)$ & NA & NA & $22(3)$ \\
\hline $\begin{array}{l}\text { Taking part in range of extra classes including physical education, } \\
\text { music, etc }\end{array}$ & $270(33)$ & $144(18)$ & $154(19)$ & $187(23)$ & $63(8)$ \\
\hline Doing homework & $295(36)$ & $285(35)$ & $75(9)$ & $152(19)$ & $11(1)$ \\
\hline Taking part in activities organised by the school & $517(63)$ & $252(31)$ & $15(2)$ & $22(3)$ & $12(1)$ \\
\hline \multicolumn{6}{|l|}{ Recreation } \\
\hline Playing sports or outdoor games & $326(40)$ & $233(28)$ & $174(21)$ & $78(10)$ & $7(1)$ \\
\hline Playing non-sporting games & $472(58)$ & $177(22)$ & $138(17)$ & $29(4)$ & $2(0)$ \\
\hline Going and watching sports events & $246(30)$ & $81(10)$ & $128(16)$ & $358(44)$ & $5(1)$ \\
\hline Taking part in artistic, cultural, or craft activities & $329(40)$ & $167(20)$ & $139(17)$ & $171(21)$ & $12(1)$ \\
\hline Going and watching artistic, or cultural events & $472(58)$ & $186(23)$ & $93(11)$ & $63(8)$ & $4(0)$ \\
\hline Taking part in tourist activities & $455(56)$ & $292(36)$ & $44(5)$ & $21(3)$ & $6(1)$ \\
\hline Getting to and moving about within local recreational facilities & 399 (49) & $167(20)$ & $148(18)$ & $87(11)$ & $17(2)$ \\
\hline Taking part in activities in local recreational facilities & $285(35)$ & $135(17)$ & $189(23)$ & $190(23)$ & $19(2)$ \\
\hline
\end{tabular}

Tables 5-7 summarise the final multivariable models. On most domains, except relationships, lower participation was associated with impairment of motor function (walking ability or fine motor skills, or both). Additionally, lower participation was associated with intellectual impairment, communication difficulties, and pain on most domains. Other specific impairments were associated with lower participation on specific domains. Odds ratios comparing difficulty in participation among children with the most and least severe impairment of walking ability ranged from 2.6 (95\% confidence interval 1.3 to 5.1 ) for recreation (table 7) to 20.5 (10 to 41) for home life (table 6). Odds ratios among children who experienced pain fairly often and those with no pain ranged from 1.9 (1.4 to 2.6) for mobility (table 6) to 5.2 (2.2 to 12 ) for relationships (table 7). Impairment and pain, however, accounted for only $4 \%$ (for the school domain, table 7) to $16 \%$ (for mealtimes and home life, table 6) of the overall deviance.

For the non-discretionary items treated separately, participation was associated with pain and impairments of walking ability, fine motor skills, and communication with a clear trend of lower participation being associated with greater impairment of walking ability and more pain. Impaired walking ability was the most important impairment in reducing participation: the odds ratio comparing difficulty in participation among children with the most and least severe impairment of walking ability was 9.6 (4.5 to 20) (table 7). 
Table $\mathbf{5}$ |Associations between participation on each domain and impairment and pain in final multilevel multivariable model

\begin{tabular}{ll}
$\begin{array}{l}\text { Life-H domain } \\
\text { Daily activities }\end{array}$ & Walking ability, fine motor skills, intellectual ability, feeding ability \\
\hline Mealtimes & Walking ability, communication, pain \\
\hline Health hygiene & Walking ability, fine motor skills, intellectual ability, pain \\
\hline Personal care & Fine motor skills, intellectual ability, communication, ataxic cerebral palsy, vision \\
\hline Communication & Walking ability, fine motor skills, intellectual ability, communication, bilateral cerebral palsy, pain \\
\hline Home life & Walking ability, intellectual ability, communication, pain \\
\hline Mobility & Fine motor skills, intellectual ability, communication, vision \\
\hline Social roles & Intellectual ability, communication, pain \\
\hline Responsibilities & Not analysed as items were not relevant to high proportion of children \\
\hline Relationships & Walking ability, intellectual ability, communication \\
\hline Community life & Walking ability, fine motor skills, intellectual ability, communication, vision, pain \\
\hline School &
\end{tabular}

Nevertheless, impairment and pain accounted for only $4 \%$ of the deviance.

None of the sociodemographic factors considered was significantly associated with participation on any domain or with non-discretionary participation. After adjustment for the child's impairment, the type of school attended was not associated with participation on any domain.

Participation-non-discretionary and on all domains except relationships — showed significant variation between regions $(\mathrm{P}<0.001)$ (tables 6 and 7$)$. The figure shows the mean level of the children's participation in each region, after adjustment for impairment and pain. The average level of participation of children in east Denmark was much higher than that of children in other regions on all domains except relationships, generally by 1-2 SD. Children in the north of England and west Sweden also had consistently high levels of participation on all domains except relationships and home life. For all domains except relationships, the variation in participation between regions was substantial compared with the overall variation in participation (tables 6 and 7): it accounted for about a third of the total variation for personal care, communication, home life, school, recreation, and non-discretionary participation (tables 6 and 7) and was even higher for mobility $(63 \%)$, mealtimes, and health hygiene $(51 \%)$ (table 6).

\section{Sensitivity analyses}

We examined residuals - that is, the differences between the level of participation predicted for each child by the statistical models in tables 6 and 7 and the child's actual level of participation. This suggested that the items within a domain might have differing abilities to discriminate between children with different levels of participation, contravening the assumptions of the statistical model. Nevertheless, when we used more flexible models that allowed different items to have different discriminatory abilities, the associations between participation and impairments on each domain were similar to those shown in tables 6 and 7, except that the association of communication difficulties with lower participation in health hygiene (table 6) was no longer apparent.

\section{Comparison with analysis using conventional scoring of} Life-H

When we used the conventional scoring of Life- $\mathrm{H},{ }^{13}$ in which help or the use of aids and adaptations lowers the participation score, most children with the greatest severity of each impairment had participation below the median. Therefore logistic regression analysis of participation above the median in each domain resulted in extremely high odds ratios for comparisons between severely impaired children and others. Furthermore, a high proportion of the deviance (42\% to $60 \%$ ) was explained by the models, with the exception of that for relationships. As in our main model, children with more severe impairment or pain had lower participation on most domains, but the types of impairment that were significantly associated with lower participation sometimes differed.

\section{DISCUSSION}

Among children with cerebral palsy, impairment of walking ability, fine motor skills, intellectual ability, communication, and parental report of pain were significantly associated with lower participation on most domains, whereas sociodemographic factors were not. Impairment and pain explained up to a sixth of the variation in participation. After adjustment for impairment and pain, children's participation varied substantially between regions, with children in Denmark having, on average, much higher participation than children in other countries on all domains except relationships. For most domains, about a third of the unexplained variation in participation could be ascribed to variation between regions and about two thirds to variation between individuals.

\section{Measuring participation}

Some instruments that measure participation such as Life-H and $\mathrm{LAQ}^{30}$ incorporate into their scoring 
Table 6 |Multilevel, multivariable regression models, relating participation for each Life-H domain in daily activities to type and level of impairment and pain of 799 children with cerebral palsy. Figures are odds ratios* $(95 \%$ confidence intervals) unless stated otherwise

\begin{tabular}{|c|c|c|c|c|c|c|}
\hline & Mealtimes & Health hygiene & Personal care & Communication & Home life & Mobility \\
\hline $\begin{array}{l}\% \text { Change in log likelihood due } \\
\text { to impairment and pain }\end{array}$ & $16 \%$ & $9 \%$ & $7 \%$ & $14 \%$ & $16 \%$ & $8 \%$ \\
\hline $\begin{array}{l}\mathrm{P} \text { for heterogeneity between } \\
\text { regions }\end{array}$ & $<0.001$ & $<0.001$ & $<0.001$ & $<0.001$ & $<0.001$ & $<0.001$ \\
\hline $\begin{array}{l}\text { Variance between regions as \% } \\
\text { of total residual variance }\end{array}$ & $51 \%$ & $51 \%$ & $27 \%$ & $33 \%$ & $36 \%$ & $63 \%$ \\
\hline \multicolumn{7}{|l|}{ Gross motor function } \\
\hline $\begin{array}{l}\text { I Walks and climbs stairs, } \\
\text { without limitation }\end{array}$ & 1.0 & 1.0 & 1.0 & NS & 1.0 & 1.0 \\
\hline II Walks inside & $1.4(1.0$ to 2.1$)$ & 2.3 (1.7 to 3.2$)$ & 3.1 (2.1 to 4.6$)$ & NS & $3.4(2.2$ to 5.3$)$ & $4.0(2.9$ to 5.5$)$ \\
\hline III Walks with assistive devices & 1.9 (1.2 to 2.8$)$ & 3.7 (2.7 to 5.2$)$ & 5.4 (3.6 to 8.3$)$ & NS & $14.8(9.0$ to 24$)$ & 5.5 (3.9 to 7.8$)$ \\
\hline $\begin{array}{l}\text { IV Unable to walk, limited self- } \\
\text { mobility }\end{array}$ & $2.4(1.5$ to 3.9$)$ & $5.3(3.7$ to 7.6$)$ & 7.9 (4.8 to 13$)$ & NS & 17.6 (10 to 31$)$ & $5.2(3.5$ to 7.6$)$ \\
\hline $\begin{array}{l}\text { V Unable to walk, severely } \\
\text { limited self mobility }\end{array}$ & $3.6(2.0$ to 6.5$)$ & 7.8 (5.1 to 12$)$ & 9.1 (4.7 to 18$)$ & NS & 20.5 (10 to 41$)$ & $7.6(4.8$ to 12$)$ \\
\hline \multicolumn{7}{|l|}{ Fine motor skills } \\
\hline I Without limitation & 1.0 & NS & 1.0 & 1.0 & 1.0 & NS \\
\hline $\begin{array}{l}\text { II Both hands limited in fine } \\
\text { skills }\end{array}$ & $3.4(2.3$ to 4.8$)$ & NS & $3.4(2.4$ to 4.9$)$ & 1.9 (1.3 to 2.7$)$ & 2.0 (1.3 to 2.9$)$ & NS \\
\hline III Needs help with tasks & $3.2(2.1$ to 4.8$)$ & NS & $4.0(2.6$ to 6.2$)$ & $2.1(1.4$ to 3.1$)$ & $2.6(1.7$ to 4.1$)$ & NS \\
\hline $\begin{array}{l}\text { IV Needs help and adapted } \\
\text { equipment }\end{array}$ & $3.5(2.0$ to 6.2$)$ & NS & $4.6(2.5$ to 8.5$)$ & $2.2(1.3$ to 3.7$)$ & $4.3(2.3$ to 8.1$)$ & NS \\
\hline V Needs total human assistance & $5.0(2.6$ to 9.7$)$ & NS & $3.1(1.5$ to 6.3$)$ & $2.9(1.7$ to 5.0$)$ & $4.1(2.0$ to 8.4$)$ & NS \\
\hline \multicolumn{7}{|l|}{ Intellectual impairment } \\
\hline$>70$ & 1.0 & NA & 1.0 & 1.0 & 1.0 & 1.0 \\
\hline $50-70$ & $1.7(1.2$ to 2.3$)$ & NA & $1.5(1.0$ to 2.0$)$ & $4.3(3.1$ to 5.9$)$ & $1.7(1.1$ to 2.4$)$ & 1.7 (1.3 to 2.3$)$ \\
\hline$<50$ & $4.8(3.4$ to 6.7$)$ & NA & $2.3(1.6$ to 3.3$)$ & $14.2(9.5$ to 21$)$ & $2.9(1.9$ to 4.5$)$ & $1.7(1.2$ to 2.4$)$ \\
\hline \multicolumn{7}{|l|}{ Communication } \\
\hline Normal speech & NS & 1.0 & NS & 1.0 & 1.0 & 1.0 \\
\hline Difficult but uses speech & NS & $2.3(1.7$ to 3.1$)$ & NS & $5.2(3.6$ to 7.5$)$ & $1.8(1.2$ to 2.7$)$ & $1.8(1.3$ to 2.5$)$ \\
\hline $\begin{array}{l}\text { Uses non-speech for formal } \\
\text { communication }\end{array}$ & NS & $1.4(1.0$ to 2.0$)$ & NS & $8.8(5.4$ to 14$)$ & $1.1(0.7$ to 1.9$)$ & $0.9(0.6$ to 1.4$)$ \\
\hline No formal communication & NS & $2.1(1.5$ to 3.1$)$ & NS & 31.4 (17 to 57$)$ & $2.6(1.4$ to 4.8$)$ & 1.8 (1.1 to 3.0$)$ \\
\hline \multicolumn{7}{|l|}{ Type of cerebral palsy } \\
\hline Spastic unilateral & NS & NS & NS & 1.0 & 1.0 & NS \\
\hline Spastic bilateral & NS & NS & NS & $1.2(0.9$ to 1.5$)$ & 1.9 (1.4 to 2.7$)$ & NS \\
\hline Dyskinetic & NS & NS & NS & 1.5 (1.0 to 2.4$)$ & $2.0(1.2$ to 3.4$)$ & NS \\
\hline Ataxic & NS & NS & NS & $4.1(2.2$ to 7.7$)$ & $2.0(1.0$ to 4.1$)$ & NS \\
\hline \multicolumn{7}{|l|}{ Feeding } \\
\hline No problems & 1.0 & NS & NS & NS & NS & NS \\
\hline Orally with difficulty & $1.8(1.3$ to 2.6$)$ & NS & NS & NS & NS & NS \\
\hline $\begin{array}{l}\text { Partial or complete feeding by } \\
\text { tube }\end{array}$ & 3.5 (2.0 to 6.3 ) & NS & NS & NS & NS & NS \\
\hline \multicolumn{7}{|l|}{ Vision } \\
\hline Has useful vision & NS & NS & NS & 1.0 & NS & NS \\
\hline No useful vision & NS & NS & NS & $2.8(1.7$ to 4.6$)$ & NS & NS \\
\hline \multicolumn{7}{|c|}{ Parental report of frequency of child pain in previous four weeks } \\
\hline None of the time & NS & 1.0 & 1.0 & NS & 1.0 & 1.0 \\
\hline Once or twice or a few times & NS & $1.4(1.1$ to 1.8$)$ & $1.5(1.2$ to 2.1$)$ & NS & $1.8(1.3$ to 2.4$)$ & $1.5(1.2$ to 2.0$)$ \\
\hline More often & NS & $2.3(1.7$ to 3.1$)$ & 2.6 (1.8 to 3.7$)$ & NS & $2.4(1.6$ to 3.5$)$ & 1.9 (1.4 to 2.6$)$ \\
\hline
\end{tabular}


Table 7|Multilevel, multivariable regression models, relating participation for each Life-H domain in social roles and nondiscretionary to type and level of impairment and pain of children with cerebral palsy. Figures are odds ratios* $(95 \%$ confidence intervals) unless stated otherwise

\begin{tabular}{|c|c|c|c|c|c|}
\hline & $\begin{array}{l}\text { Responsibilities } \\
(\mathrm{n}=798)\end{array}$ & $\begin{array}{l}\text { Relationships } \\
\quad(n=798)\end{array}$ & $\begin{array}{l}\text { School } \\
(n=795)\end{array}$ & $\begin{array}{c}\text { Recreation } \\
(n=799)\end{array}$ & $\begin{array}{l}\text { Non-discretionary } \\
(\mathrm{n}=799)\end{array}$ \\
\hline $\begin{array}{l}\% \text { Change in log likelihood due to } \\
\text { impairment and pain }\end{array}$ & $13 \%$ & $5 \%$ & $4 \%$ & $8 \%$ & $4 \%$ \\
\hline P for heterogeneity between regions & $<0.001$ & 0.009 & $<0.001$ & $<0.001$ & $<0.001$ \\
\hline $\begin{array}{l}\text { Variance between regions as \% of total } \\
\text { residual variance }\end{array}$ & $15 \%$ & $5 \%$ & $34 \%$ & $35 \%$ & $38 \%$ \\
\hline \multicolumn{6}{|l|}{ Gross motor function } \\
\hline $\begin{array}{l}\text { Walks and climbs stairs, without } \\
\text { limitation }\end{array}$ & NS & NS & 1.0 & 1.0 & 1.0 \\
\hline Walks inside & NS & NS & 2.3 (1.6 to 3.4$)$ & 2.5 (1.7 to 3.7$)$ & $3.4(2.3$ to 5.1$)$ \\
\hline Walks with assistive devices & NS & NS & $3.0(2.0$ to 4.4$)$ & $3.6(2.3$ to 5.5$)$ & $6.4(4.1$ to 10$)$ \\
\hline Unable to walk, limited self mobility & NS & NS & $3.3(2.1$ to 5.3$)$ & 2.5 (1.5 to 4.2$)$ & $9.6(5.5$ to 17$)$ \\
\hline $\begin{array}{l}\text { Unable to walk, severely limited self } \\
\text { mobility }\end{array}$ & & & $3.5(2.1$ to 5.8$)$ & $2.6(1.3$ to 5.1$)$ & $9.6(4.5$ to 20$)$ \\
\hline \multicolumn{6}{|l|}{ Fine motor skills } \\
\hline Without limitation & 1.0 & NS & NS & 1.0 & $1.0-$ \\
\hline Both hands limited in fine skills & 2.4 (1.6 to 3.6$)$ & NS & NS & $1.9(1.3$ to 2.7$)$ & 2.5 (1.7 to 3.7$)$ \\
\hline Needs help with tasks & 2.6 (1.6 to 4.2$)$ & NS & NS & 2.8 (1.8 to 4.4$)$ & 3.3 (2.1 to 5.2$)$ \\
\hline Needs help and adapted equipment & $1.9(1.0$ to 3.6$)$ & NS & NS & $2.7(1.4$ to 5.1$)$ & $4.0(2.0$ to 8.2$)$ \\
\hline Needs total human assistance & $3.1(1.5$ to 6.3$)$ & NS & NS & 4.0 (1.9 to 8.5$)$ & $2.7(1.2$ to 6.3$)$ \\
\hline \multicolumn{6}{|l|}{ Intellectual impairment } \\
\hline 170 & 1.0 & 1.0 & 1.0 & 1.0 & NS \\
\hline $50-70$ & $6.3(4.2$ to 9.4$)$ & $1.9(0.8$ to 4.2$)$ & $1.6(1.1$ to 2.2$)$ & 2.3 (1.6 to 3.2$)$ & NS \\
\hline$<50$ & $26.2(15$ to 44$)$ & $4.6(1.7$ to 12$)$ & 2.3 (1.5 to 3.5$)$ & 5.6 (3.6 to 8.7$)$ & NS \\
\hline \multicolumn{6}{|l|}{ Communication } \\
\hline Normal speech & 1.0 & 1.0 & 1.0 & 1.0 & 1.0 - \\
\hline Difficulty but uses speech & 2.5 (1.5 to 3.9$)$ & $3.3(1.3$ to 8.2$)$ & $2.0(1.4$ to 3.0$)$ & $1.8(1.2$ to 2.7$)$ & $3.0(2.0$ to 4.6$)$ \\
\hline $\begin{array}{l}\text { Uses non-speech for formal } \\
\text { communication }\end{array}$ & $4.4(2.3$ to 8.2$)$ & 2.4 (0.8 to 6.9$)$ & 1.4 (0.8 to 2.3$)$ & 1.3 (0.8 to 2.2$)$ & 1.6 (1.0 to 2.8$)$ \\
\hline No formal communication & $16.0(7.4$ to 35$)$ & $7.9(2.6$ to 24$)$ & 2.9 (1.6 to 5.4$)$ & $2.7(1.5$ to 5.1$)$ & $2.4(1.3$ to 4.4$)$ \\
\hline \multicolumn{6}{|l|}{ Type of cerebral palsy } \\
\hline Spastic unilateral & NS & NS & NS & NS & NS \\
\hline Spastic bilateral & NS & NS & NS & NS & NS \\
\hline Dyskinetic & NS & NS & NS & NS & NS \\
\hline Ataxic & NS & NS & NS & NS & NS \\
\hline \multicolumn{6}{|l|}{ Feeding } \\
\hline No problems & NS & NS & NS & NS & NS \\
\hline Orally with difficulty & NS & NS & NS & NS & NS \\
\hline Partial or complete feeding by tube & NS & NS & NS & NS & NS \\
\hline \multicolumn{6}{|l|}{ Vision } \\
\hline Has useful vision & 1.0 & NS & NS & 1.0 & NS \\
\hline No useful vision & $5.2(2.5$ to 11$)$ & NS & NS & $3.0(1.8$ to 5.1$)$ & NS \\
\hline \multicolumn{6}{|c|}{ Parental report of frequency of child pain in previous four weeks } \\
\hline None of the time & NS & 1.0 & NS & 1.0 & $1.0-$ \\
\hline Once or twice or a few times & NS & 1.8 (0.9 to 3.6$)$ & NS & $1.6(1.2$ to 2.2$)$ & $1.6(1.1$ to 2.2$)$ \\
\hline More often & NS & $5.2(2.2$ to 12$)$ & NS & 2.5 (1.7 to 3.6$)$ & $2.7(1.8$ to 4.1$)$ \\
\hline \multicolumn{6}{|c|}{$\begin{array}{l}\text { NS=factors not significantly associated with participation on specific domains. Additionally, no sociodemographic factor considered (child's age and } \\
\text { sex, number of siblings and whether they were disabled, type of parental employment, level of parental educational qualifications, whether the family } \\
\text { lived in an urban or rural area) was significantly associated with participation on any domain. } \\
\text { *Odds ratios from latent regression ordinal item response models, except for non-discretionary which are from latent regression Rasch model (see } \\
\text { bmj.com). Odds ratios }>1 \text { indicate greater difficulty in participation in children in that category. }\end{array}$} \\
\hline
\end{tabular}

system the help required by the child to perform an activity. We used Life-H, grouping the items into the domains proposed by the developers of the instrument, but we based our main analysis on the responses to each item without modifying them if the child needed help to participate. This resulted in the magnitude of the effect of impairment on participation being much smaller and less of the variation in participation being accounted for by impairment, compared with analysis with the conventional scoring of Life-H. This 


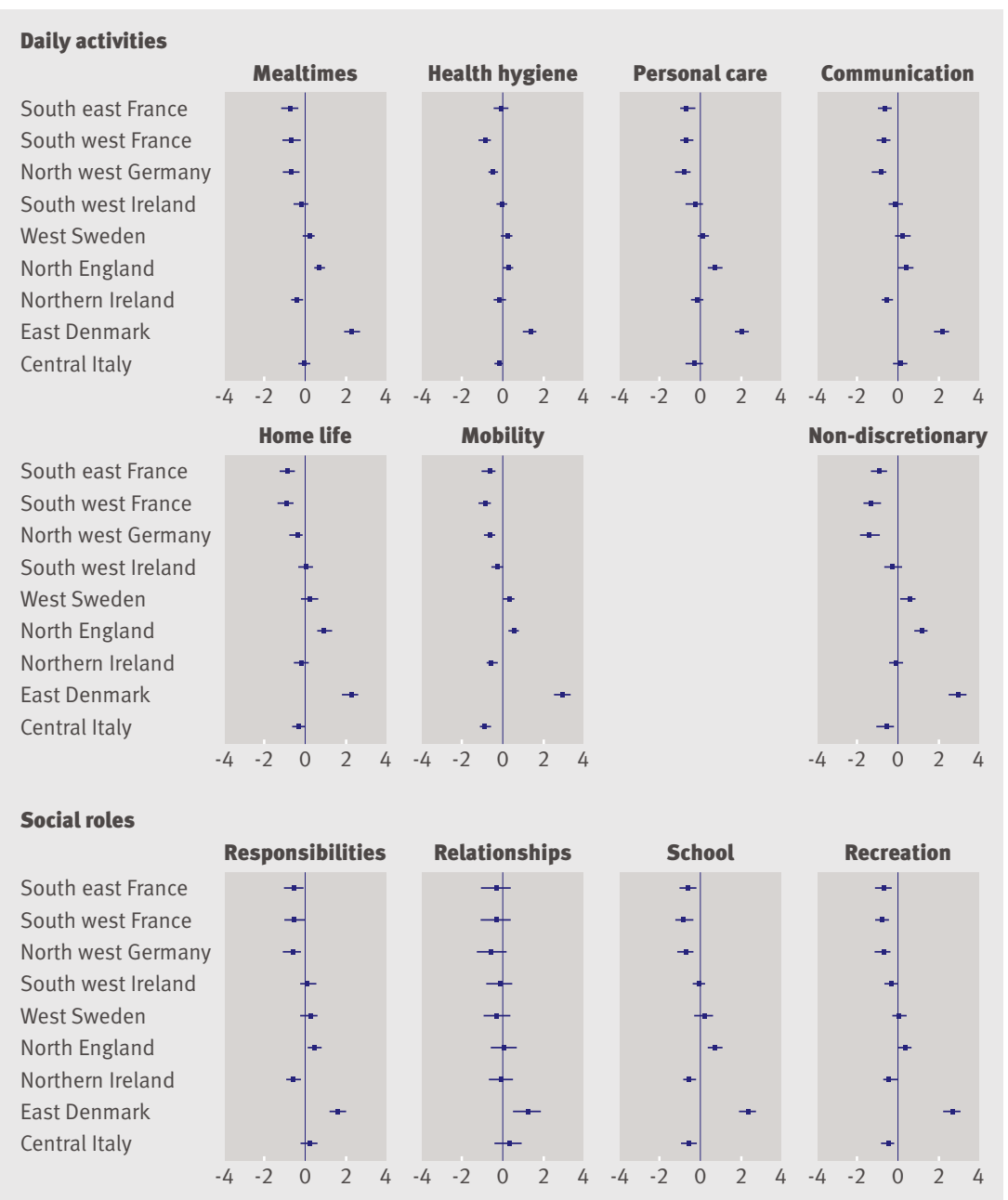

Mean level (with $95 \%$ confidence intervals) of children's participation in each region, adjusted for impairment and pain. Higher scores indicate higher participation. Mean adjusted participation is zero and each unit is 1 SD of residual variation between children

would explain why previous studies that included aids and adaptations in the scoring system found between $55 \%$ and $70 \%$ of the variation in participation explained by impairment. ${ }^{3132}$ Allowing aids, adaptations, and help to influence the participation score makes the implicit assumption that participation with environmental help is inferior to that without such help, and inevitably overestimates the strength of the relation between impairment and participation. Furthermore, our findings confirmed the limitations of the Life-H instrument in the domains of community life ${ }^{13}$ and school and personal care. ${ }^{33}$

Simply recording whether or not children participate in life situations might not capture important differences between children. Frequency of participation might allow more appropriate comparison of discretionary participation between disabled children and children in the general population. Use of the CAPE instrument,${ }^{34}$ which captures frequency rather than difficulty of participation and does not incorporate assistance needed into the scoring system, should be considered in future studies.

\section{Strengths and limitations of the study}

We included a large representative sample of children with cerebral palsy in nine European regions, eight of which had population based registers. We included all children regardless of their impairments, carried out robust statistical analyses of participation in relation to a wide range of impairments, pain, and sociodemographic factors; and assessed geographical variation.

Although just over a third of the families of children with cerebral palsy who were sampled did not participate in the study, the regressions stratified the children by factors associated with non-response (region and walking ability), which should reduce bias. ${ }^{23}$ Nevertheless the participation of non-responders might have been systematically different from that of responders, so some bias could be present.

We considered alternative explanations for the differences that we found between regions. As the rate of non-response varied between regions, ${ }^{23}$ differences in the level of participation might, at least in part, be because of differences in response rates. This seems unlikely, however, as south west Ireland and central Italy had similar levels of non-response to east Denmark but different levels of participation. Different researchers visited the families in each region, which might have introduced systematic differences into parents' responses. We minimised this risk by training the researchers together at dedicated workshops. As the questionnaires were in different languages, the precise meaning of the questions might have been slightly different in each language. We minimised this risk by forward and backward translations according to international guidelines. ${ }^{3536}$ Language differences seem an unlikely explanation of the regional differences as children in north England had consistently higher participation than Irish children, despite their common language. Regions might differ in the type of participation to which they aspire for their children; however, non-discretionary participation-which is unlikely to be culturally determined-showed similar regional heterogeneity to discretionary participation. We plan to publish a further report assessing how environmental factors are associated with participation. We hope this will identify some of the factors that explain regional differences in levels of participation of children.

\section{Comparison with other studies}

The results of some studies that also used multivariable models differ from ours. The large number of children in our study, randomly sampled from population registers gives weight to our findings. We also considered a wider range of impairments than many studies. Because impairments are highly correlated with each other, studies that assessed fewer impairments might identify different dominant associations. Finally one of the studies cited below ${ }^{37}$ reported participation using the PEDI, ${ }^{38}$ which is closer to a measure of function than of participation. ${ }^{39}$ The strong associations between severity of motor impairment and intellectual impairment and lower participation confirm results of 


\section{WHAT IS ALREADY KNOWN ON THIS TOPIC}

Participation, defined as involvement in life situations, is important for all children

Disabled children have reduced participation, partly because of their intrinsic impairments

The social model of disability proposes that participation of disabled people depends not only on their impairments but also on the social, physical, and attitudinal environment in which they live

\section{WHAT THIS STUDY ADDS}

After adjustment for severity of impairment, pain is strongly associated with lower participation in children with cerebral palsy and should therefore be carefully assessed

Participation varies substantially across nine European regions, as predicted by the social model of disability

National regulation and legislation should be directed to ensuring all countries adapt environments to optimise the participation of disabled children, building on the experience of those countries that make best provision other studies. ${ }^{18374041}$ Results of studies of other impairments-such as epilepsy, ${ }^{18374041}$ communication difficulty, ${ }^{4041}$ and sensory impairments ${ }^{1841}$-were sometimes similar to ours and sometimes different.

Our results confirm the finding of geographical heterogeneity suggested by a smaller study. ${ }^{40}$ We found substantial variation between regions in the participation of disabled children, with much better participation in Denmark across all domains except relationships. These differences might be partly explained by the different policies and legislation directed to equality and information, education, social security, support and care services, health services, assistive technology, and physical environment in the different countries. We have collated those affecting disabled children for the countries in our study. ${ }^{4243}$ Advocacy groups for disabled people have worked with policy makers in Denmark to ensure that every sector implements the principle of equal access. This results in, for example, sports clubs, restaurants, and cultural centres having to ensure they are suitable for disabled children. Denmark has a public system of after school clubs attended every day by most children up to age 12, whether disabled or not. Denmark and Sweden have central national resources for providing information to families of disabled children about assistive technology whereas the other countries do not. They also have policies for social care that explicitly emphasise the social model in determining access to support services. In terms of financial assistance to poor families (whether with a disabled child or not), Denmark is ahead of other countries, with UK and Ireland following and Italy well behind. National policies on transport are also likely to be relevant to participation of disabled children. All countries in the study except Italy had a national scheme to ensure that families could have an adapted private vehicle to transport their child. All countries make arrangements for adapted vehicles to take a child to and from school but in Denmark, Sweden, and increasingly Germany such transport is more widely provided to include taking children to after school clubs and other social events.

We did not examine the contribution of familial factors, which might partly account for the unexplained variation in participation between individuals, but a recent Canadian study did so. It found that child impairment, child behaviour and personality, and family recreational styles predicted about a third of the variation of leisure and recreational participation. ${ }^{44}$ From a societal perspective, the most important predictors of participation are those that are amenable to change. Child personality and family recreational styles are not amenable to state intervention whereas the environment is. "The individual is rarely going to be altered very much whereas the environment slowly but surely can." ${ }^{45}$

\section{Implications for research and practice}

Children with cerebral palsy have lower participation than children in the general population, ${ }^{2146}$ and those with more types of impairment and with more severe impairments have lower participation across most domains. This picture is quite different from that for quality of life ${ }^{29}$ which is less influenced by impairment and is broadly similar between children with cerebral palsy and the general population. This contrast between participation and quality of life is strong evidence for their separate nature and for the need to assess both in clinical practice. Quality of life is a person's subjective assessment of what they feel about their life, whereas a person's participation is an objective account of what the person does. Assessment of participation should enable the child and family to identify areas of life in which they want greater participation and so influence the choice of medical, therapeutic, and environmental interventions. Such practice is beginning to happen. ${ }^{4748}$

In recent years it has been recognised that many children with cerebral palsy have frequent and severe pain, ${ }^{49-51}$ and our study makes clearer its association with lower participation. As pain is also known to have a pervasive effect on quality of life, ${ }^{29}$ better assessment and treatment of pain should improve both participation and quality of life. Firstly, clinicians should ask about children's pain. Children with cerebral palsy might have always lived with pain and might assume this to be normal; discussion of such pain is itself helpful. ${ }^{52}$ In one study, assisted stretching was the daily living activity most commonly identified as painful, ${ }^{53}$ which reinforces the need to strengthen the evidence base for the long term benefit of therapeutic interventions if they have such an important disadvantage as pain. Psychological factors play an important part in most chronic pain, and the importance of the place of interventions such as cognitive behavioural therapy has been emphasised for older children with cerebral palsy. ${ }^{54}$

The considerable variation in participation between regions suggests that some countries promote participation better than others through policies and regulation at national level. Some variation might also be 
accounted for by the extent to which families can actually access aspects of the environment they need; local availability might not correspond to what national guidance or policy intends. We will explore this possibility by using data from the same study from a questionnaire designed to capture these unmet needs. Analysis of the causes of the geographical heterogeneity should provide evidence for changes to regulation and legislation and for better direction of resources and so respond to the duty to provide accessibility under Article 9 of the UN Convention on the Rights of Persons with Disabilities. ${ }^{2}$

The best way to characterise and measure participation must continue to be debated. ${ }^{533}$ New instruments need to be developed that incorporate frequency and quality of participation and fulfil modern psychometric requirements for scale development.

We thank the families who participated in SPARCLE and the study's research associates-Kerry Anderson, Barbara Caravale, Malin Carlsson, Eva Lise Eriksen, Delphine Fenieys, Bettina Gehring, Louise Gibson, Heid Kiecksee, Ann Madden, and Ondine Pez-for their enthusiasm and dedication to contacting families and collecting high quality data. Contributors: AC participated in planning, coordinated the study, wrote the paper, and took overall responsibility for the delivery of the work. AC had full access to all the data in the study, final responsibility for the decision to submit for publication, and is guarantor. JF participated in planning, was responsible for data collection, attended workshops planning analysis, and wrote the paper. UT, CA, EB, VMcM, SIM, and JP participated in planning the study, were responsible for data collection, and attended workshops planning analysis. HOD performed the statistical analysis, participated in maintaining the quality of the data, and wrote the paper. KNP was responsible for the day to day administration of the study and data collection in one centre and participated in maintaining the quality of the data. MM was involved in this study in its later stages and attended workshops. All authors saw and approved the final version. Funding: The study was funded by the European Union Research Framework 5 Programme, grant number QLG5-CT-2002-00636. The German region joined later, funded by Bundesministerium für Gesundheit/German Ministry of Health (GRR-58640-2/14) and Stiftung für das Behinderte Kind/Foundation for the Disabled Child. The funders had no role in the study design; collection, analysis and interpretation of data; writing of the report; or decision to submit for publication. Competing interests: None declared.

Ethical approval: This study was approved by ethics committees in each country. All parents gave written consent. All children with sufficient cognitive capacity gave written consent or communicated consent if unable to write.

1 United Nations. Convention on the rights of the child. New York United Nations, 1989.

2 United Nations. Convention on the rights of persons with disabilities. Resolution 60/232. Adopted 13 December 2006. New York: United Nations, 2006.

3 World Health Organization. International classification of functioning, disability and health. Geneva: WHO, 2001.

4 World Health Organization. World Health Organization classification of functioning, disability and health. Children and youth version. Geneva: WHO, 2007.

5 McConachie H, Colver AF, Forsyth RJ, Jarvis SN, Parkinson KN. Participation of disabled children: how should it be characterised and measured? Disabil Rehabil 2006;28:1157-64.

6 Coster W, Khetani MA. Measuring participation of children with disabilities: Issues and challenges. Disabil Rehabil 2007;30:639-48.

7 Oliver M. The politics of disablement. London: Macmillan, 1990.

8 Majnemer A, Mazer B. New directions in the outcome evaluation of children with cerebral palsy. Semin Pediatr Neurol 2004;11:11-7.

9 Fougeyrollas P, Noreau L, Bergeron H, Cloutier R, Dion SA, St-Michel G. Social consequences of long term impairments and disabilities: conceptual approach and assessment of handicap. Int J Rehabil Res 1998;21:127-41.

10 Prevalence and characteristics of children with cerebral palsy in Europe. Dev Med Child Neurol 2002;44:633-40.
11 Rosenbaum P. Cerebral palsy: what parents and doctors want to know. BMJ 2003;326:970-4.

12 Liptak GS, Accardo PJ. Health and social outcomes of children with cerebral palsy. J Pediatr 2004;145(2 suppl):S36-41.

13 Noreau L, Lepage C, Boissiere L, Picard R, Fougeyrollas P, Mathieu J, et al. Measuring participation in children with disabilities using the assessment of life habits. Dev Med Child Neurol 2007;49:666-71.

14 Kerr C, McDowell B, McDonough S. The relationship between gross motor function and participation restriction in children with cerebra palsy: an exploratory analysis. Child Care Health Dev 2007;33:22-7.

15 Law M, King G, King S, Kertoy M, Hurley P, Rosenbaum P, et al. Patterns of participation in recreational and leisure activities among children with complex physical disabilities. Dev Med Child Neurol 2006;48:337-42.

16 Samson-Fang L, Fung E, Stallings VA, Conaway M, Worley G, Rosenbaum P, et al. Relationship of nutritional status to health and societal participation in children with cerebral palsy. J Pediatr 2002;141:637-43

17 Battaglia M, Russo E, Bolla A, Chiusso A, Bertelli S, Pellegri A, et al. International classification of functioning, disability and health in a cohort of children with cognitive, motor, and complex disabilities. Dev Med Child Neurol 2004;46:98-106.

18 Beckung E, Hagberg G. Neuroimpairments, activity limitations, and participation restrictions in children with cerebral palsy. Dev Med Child Neurol 2002;44:309-16.

19 Maher CA, Williams MT, Olds T, Lane AE. Physical and sedentary activity in adolescents with cerebral palsy. Dev Med Child Neurol 2007;49:450-7.

20 Van Zelst BR, Miller MD, Russo RN, Murchland S, Crotty M. Activitie of daily living in children with hemiplegic cerebral palsy: a crosssectional evaluation using the assessment of motor and process skills. Dev Med Child Neurol 2006;48:723-7.

21 Schenker R, Coster W, Parush S. Participation and activity performance of students with cerebral palsy within the school environment. Disabil Rehabil 2005;27:539-52.

22 Colver A. Study protocol: SPARCLE-a multi-centre European study of the relationship of environment to participation and quality of life of children with cerebral palsy. BMC Public Health 2006;6:105.

23 Dickinson H, Parkinson K, McManus V, Arnaud C, Beckung E, Fauconnier J, et al. Assessment of data quality in a multi-centre crosssectional study of participation and quality of life of children with cerebral palsy. BMC Public Health 2006;6:273.

24 Lepage C, Noreau L, Bernard PM, Fougeyrollas P. Profile of handicap situations in children with cerebral palsy. Scand J Rehabil Med 1998;30:263-72.

25 Landgraf J, Abetz L, Ware JE. Child health questionnaire (CHO): a user's manual. Boston, MA: HealthAct, 1999.

26 Palisano R, Rosenbaum P, Walter S, Russell D, Wood E, Galuppi B. Development and reliability of a system to classify gross moto function in children with cerebral palsy. Dev Med Child Neurol 1997;39:214-23.

27 Skrondal A, Rabe-Hesketh S. Generalized latent variable modelling: multilevel, longitudinal, and structural equation models. London: Chapman \& Hall, 2004

28 Rabe-Hesketh S, Skrondal A, Pickles A. Maximum likelihood estimation of limited and discrete dependent variable models with nested random effects. J Econometrics 2005;128:301-23.

29 Dickinson HO, Parkinson KN, Ravens-Sieberer U, Schirripa G, Thyen U, Arnaud C, et al. Self-reported quality of life of 8-12-year-old children with cerebral palsy: a cross-sectional European study. Lancet 2007;369:2171-8.

30 Jessen EC, Colver AF, Mackie PC, Jarvis SN. Development and validation of a tool to measure the impact of childhood disabilities on the lives of children and their families. Child Care Health Dev 2003;29:21-34.

31 Van Meeteren J, Roebroeck ME, Celen E, Donkervoort M, Stam HJ. Functional activities of the upper extremity of young adults with cerebral palsy: a limiting factor for participation? Disabil Rehabil 2008;30:387-95.

32 Forsyth R, Colver A, Alvanides S, Woolley M, Lowe M. Participation of young severely disabled children is influenced by their intrinsic impairments and environment. Dev Med Child Neurol 2007;49:345-9.

33 Morris C. Measuring children's participation. Dev Med Child Neurol 2007;49:645.

34 King GA, Law M, King S, Hurley P, Hanna S, Kertoy M, et al. Measuring children's participation in recreation and leisure activities: construct validation of the CAPE and PAC. Child Care Health Dev 2007;33:28-39.

35 Acquadro C, Jambon B, Ellis D, Marquis P. Language and translation issues. In: Spilker B, ed. Quality of life and pharmacoeconomics in clinical trials. Philadelphia: Lippincott-Raven, 1996:575-9.

36 Beaton DE, Bombardier C, Guillemin F, Ferraz MB. Guidelines for the process of cross-cultural adaptation of self-report measures. Spine 2000;25:3186-91. 
37 Voorman JM, Dallmeijer AJ, Schuengel C, Knol DL, Lankhorst GJ, Becher JG. Activities and participation of 9 to13-year-old children with cerebral palsy. Clin Rehabil 2006;20:937-48.

38 Feldman AB, Haley SM, Coryell J. Concurrent and construct validity of the pediatric evaluation and disability inventory. Phys Ther 1990;70:602-10.

39 Sakzewski L, Boyd R, Ziviani J. Clinimetric properties of participation measures for 5 to13-year-old children with cerebral palsy: a systematic review. Dev Med Child Neurol 2007;49:232-40.

40 Hammal D, Jarvis S, Colver A. Participation of children with cerebral palsy is influenced by where they live. Dev Med Child Neurol 2004;46:292-8.

41 Morris C, Kurinczuk JJ, Fitzpatrick R, Rosenbaum PL. Do the abilities of children with cerebral palsy explain their activities and participation? Dev Med Child Neurol 2006;48:954-61.

42 Tisdall K. National contextual factors affecting the lives of disabled children in Denmark, France, Germany, Ireland, Italy, Sweden and UK (England and Northern Ireland). Vol 1. Newcastle: Newcastle University,

2006. www.ncl.ac.uk/sparcle/Publications_files/WebVol1.pdf.

43 Tisdall K. National contextual factors affecting the lives of disabled children in Denmark, France, Germany, Ireland, Italy, Sweden and UK (England and Northern Ireland). Vol 2. Newcastle: Newcastle University,

2006. www.ncl.ac.uk/sparcle/Publications_files/WebVol2.pdf.

44 King G, Law M, Hanna S, King S, Hurley P, Rosenbaum P, et al. Predictors of the leisure and recreation participation of children with physical disabilities: a structural equation modeling analysis. Child Health Care 2006;35:209-34.

45 Shakespeare T, Watson N. The social model of disability: an outdated ideology? Research in Social Science and Disability 2002;2:9-28.
46 Michelsen SI, Flachs E, Uldall P, Eriksen E, McManus V, Parkes J, et al. Frequency of participation of 8-12-year-old children with cerebral palsy; a multi-centre cross-sectional European study. Eur J Paediatr Neurol 2008;13:165-77.

47 Bedell GM, Dumas HM. Social participation of children and youth with acquired brain injuries discharged from inpatient rehabilitation a follow-up study. Brain Inj 2004;18:65-82.

48 Kertoy M, Law M, King G, Petrenchik T, Rosenbaum P. Children's assessment of participation and enjoyment and preferences for activities of children: clinical utility and application to intervention planning. Dev Med Child Neurol 2008;50(suppl 114):114-20.

49 Houlihan CM, O’Donnell M, Conaway M, Stevenson RD. Bodily pain and health-related quality of life in children with cerebral palsy. Dev Med Child Neurol 2004;46:305-10.

50 Tervo RC, Symons F, Stout J, Novacheck T. Parental report of pain and associated limitations in ambulatory children with cerebral palsy. Arch Phys Med Rehabil 2006;87:928-34.

51 Engel JM, Petrina TJ, Dudgeon BJ, McKearnan KA. Cerebral palsy and chronic pain: a descriptive study of children and adolescents. Phys Occup Ther Pediatr 2005;25:73-84.

52 Castle K, Imms C, Howie L. Being in pain: a phenomenological study of young people with cerebral palsy. Dev Med Child Neurol 2007;49:445-9.

53 Hadden $\mathrm{KL}$, von Baeyer CL. Pain in children with cerebral palsy: common triggers and expressive behaviors. Pain 2002;99:281-8.

54 Engel JM, Schwartz L, Jensen MP, Johnson DR. Pain in cerebral palsy: the relation of coping strategies to adjustment. Pain 2000;88:225-30.

Accepted: 21 January 2009 